\title{
Measurements of the Total Electron Content and the Equivalent Slab Thickness of the Midlatitude Ionosphere
}

\author{
R. V. Bhonsle, Aldo V. da Rosa, and O. K. Garriott \\ Radioscience Laboratory, Stanford University, Stanford, Calif.
}

(Received February 16, 1965)

\begin{abstract}
The total electron content $N_{T}$ and the equivalent slab thickness $\tau$ of the midlatitude ionosphere are determined from differential Doppler measurements on the radio transmissions from the Transi 4. A satellite and the ionosonde data near Washington, D.C., and Ottawa. The trends of diurnal, seasonal, and sunspot cycle variations of $N_{T}$ and $\tau$ at midday are described. It is found that in 1962 both $N_{T}$ and $\tau$ were considerably decreased in magnitude as compared to the corresponding values near the peak of the sunspot cycle. The inferred mean electron-ion temperature is found to be generally in excess of the neutral gas temperature. The ratio $T_{e} / T_{g}$ in the daytime is estimated to be 1.8 in summer and about 1.1 to 1.2 in winter, which may reflect corresponding changes in the ratio $Q / N_{e}^{2}$, where $Q$ is the heat input to the electrons and $N_{e}$ is the electron density. The relationship between $\tau$ and $K_{p}$ appears to be rather ambiguous in contrast with the positive correlation between the neutral gas temperature and $K_{p}$.
\end{abstract}

\section{Introduction}

The radio transmissions from artificial earth satellites have been very useful in the exploration of the ionosphere, particularly for the measurements of the total electron content, $N_{T}$, up to the height of the satellite and for studying ionospheric irregularities. The characteristics of the satellite radio signals such as amplitude, frequency, phase, and direction of arrival may all undergo significant changes during their passage through the ionosphere, provided the frequency of the radiation is not too large in comparison with the critical frequency of the $F$ region of the ionosphere.

Measurements of the Faraday fading of the satellite signals have been used to calculate $N_{T}$ by [Garriott, 1960; Little and Lawrence, 1960; Blackband, 1960; Yeh and Swenson, 1961; Blumle, 1962; Lawrence et al., 1963; Rogers, 1964] and others. Measurements involving Doppler frequency shifts have been used to calculate $N_{T}$ by [Aitchison et al., 1959; Ross, 1960; de Mendonca, 1962, and Hibberd 1964]. Garriott and de Mendonca [1963] showed that the most accurate method of obtaining $N_{T}$ is a hybrid analysis using simultaneous Faraday and Doppler data. Recently, Titheridge [1964] determined the diurnal and seasonal variations of $N_{T}$ and the scale height, $H$, of the $F$ region, by measuring the vertical angle of arrival of the $20-\mathrm{MHz}$ radio signals from Explorer 7 at Auckland over a period of 16 months in 1960-61 (refraction method). Measurements of the equivalent slab thickness, $\tau$, defined as the ratio of $N_{T}$ measured by satellite observation to the corresponding maximum electron density of the $F$ region, $N_{\max }$, have been discussed by [Ross, 1960; Ross and Anderson, 1962; Rogers, 1964; and Hibberd, 1964].
The present paper describes the results of the analysis of the differential Doppler data received near Washington, D.C., by the Johns Hopkins University on two pairs of harmonically related frequencies (54$324 \mathrm{MHz}$ and $150-400 \mathrm{MHz}$ ) transmitted from Transit 4A during 1962, a period of low solar activity. The method of calculating $N_{T}$ has been described elsewhere [sec. 3.4, Garriott and de Mendonca, 1963]. Mean diurnal, seasonal, and solar cycle variations of $N_{T}$ and $\tau$ of the midlatitude ionosphere will be described and compared with the results obtained by other workers.

\section{Experimental Data}

Of 702 satellite recordings available from February 1962 to September 1962, only 259 were used in the present study. The remaining 443 recordings were rejected either because the satellite ephemeris was not available or the recordings were so much disturbed that the "proximal point" of the satellite could not be determined. The intersection of the propagation ray path with a concentric spherical shell at the height of $350 \mathrm{~km}$ is called the ionospheric point, and its vertical projection on the ground is the subionospheric point. A few sample plots of $N_{T}$ against geographic latitude of the subionospheric point are shown in figure 1. While it is easy to obtain an almost continuous distribution of $N_{T}$ over a small range of latitudes about the satellite receiving station, it is difficult to obtain the corresponding distribution of $\tau$ owing to the sparsity of ionosonde stations. Therefore, we shall restrict ourselves to the diurnal and seasonal variations of the ionosphere over two midlatitude stations, namely, Washington, D.C. $\left(40^{\circ}\right.$ geographic) and Ottawa $\left(45^{\circ} .4\right.$ geographic) for which both $N_{T}$ and $N_{\max }$ values were available. $N_{\max }$ 


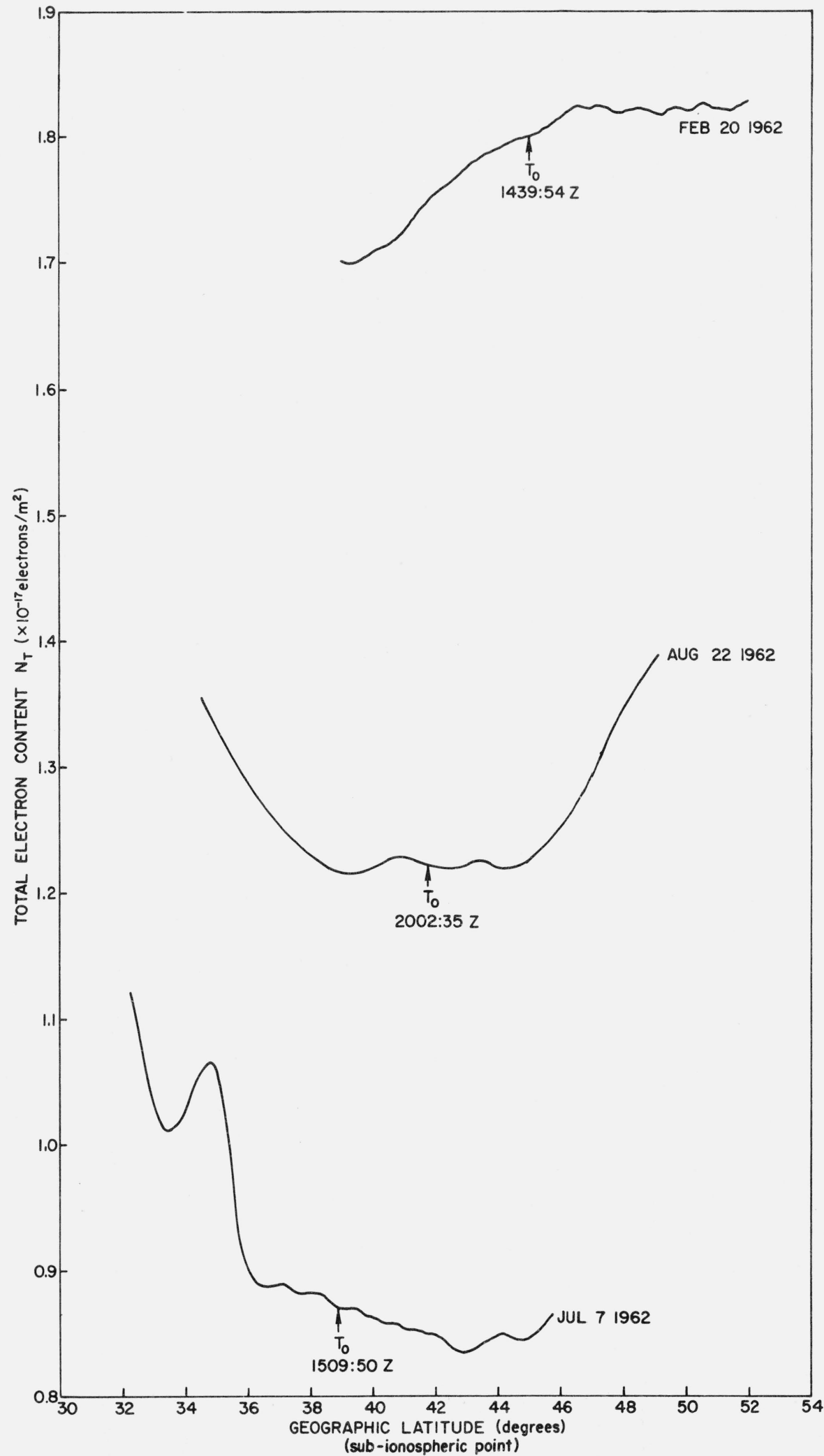

FIGURE 1. Some sample plots of $\mathrm{N}_{\mathrm{T}}$ against geographic latitude of the subionospheric point of Transit 4A satellite in 1962.

$T_{0}$ represents the proximal point of satellite passage. 
values for $\mathrm{W}$ ashington and Ottawa were taken from the published ionosonde data. All $N_{\max }$ values were interpolated to the corresponding local time of the satellite passage.

\section{Results of the Analysis}

\subsection{Diurnal and Seasonal Variations of $\boldsymbol{N}_{T}$}

Figures $2 \mathrm{a}$ and $2 \mathrm{~b}$ show the values of $N_{T}$ up to the height of the satellite (usually greater than $880 \mathrm{~km}$ ) over Washington and Ottawa respectively, obtained from the analysis of the differential Doppler data of Transit 4A satellite during the period February 1962 to September 1962. These values of $N_{T}$ were scaled from the latitudinal plots of $N_{T}$ for both the northbound and southbound passages of the satellite. The local times and the months of observations are shown at the bottom of the figures. The smoothed sunspot number, $\bar{R}$, decreased from 42 to 32 during the observing period. Although 13 geomagnetic disturbances were reported during this period, none of them was classified as severe. The storm indices ranged from $A=10$ to $A=40$, with a median of about 25 . (Storms with $A$ indices of about 50 or higher are classified as severe.) Therefore, all the available values of $N_{T}$ were plotted in figures 2a and 2b. Although there is scatter in the values of $N_{T}$ on the order of \pm 30 percent the diurnal variation of about 6 to 1 can be clearly seen both at Washington and Ottawa. Scatter of $N_{T}$ is believed to occur mainly due to large day-to-day changes in the ionosphere and is not an indication of measurement error.

For the purpose of comparing $N_{T}$ near the latitude of Washington $\left(40^{\circ} \mathrm{N}\right)$ and that of Ottawa $\left(45^{\circ} \mathrm{N}\right)$, the
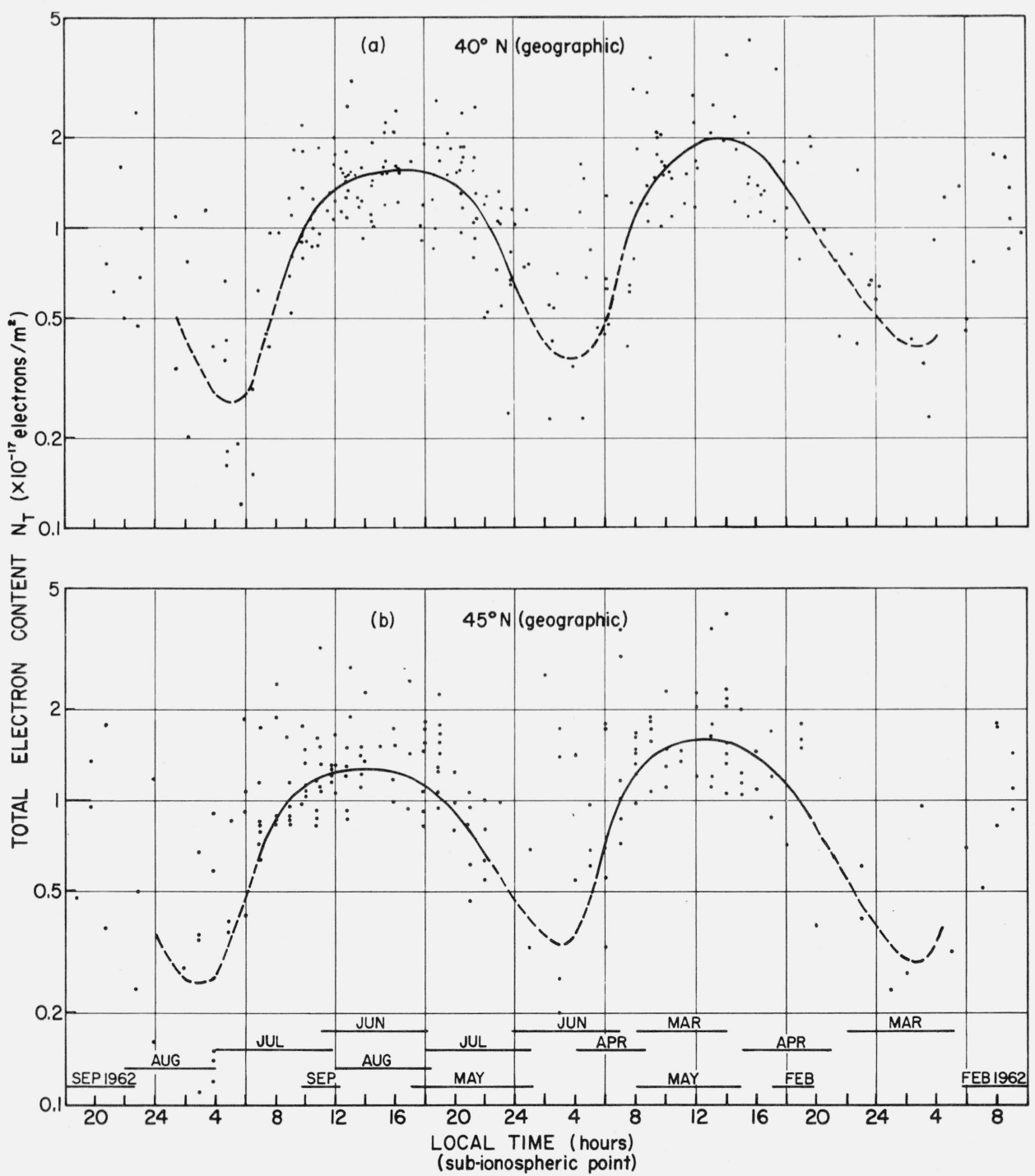

FIGURE 2. The total electron content $\mathrm{N}_{\mathrm{T}}$ of the ionosphere deduced from Transit $4 A$ differential Doppler measurements at (a) $40^{\circ} \mathrm{N}$ and (b) $45^{\circ} \mathrm{N}$ geographic latitudes. 


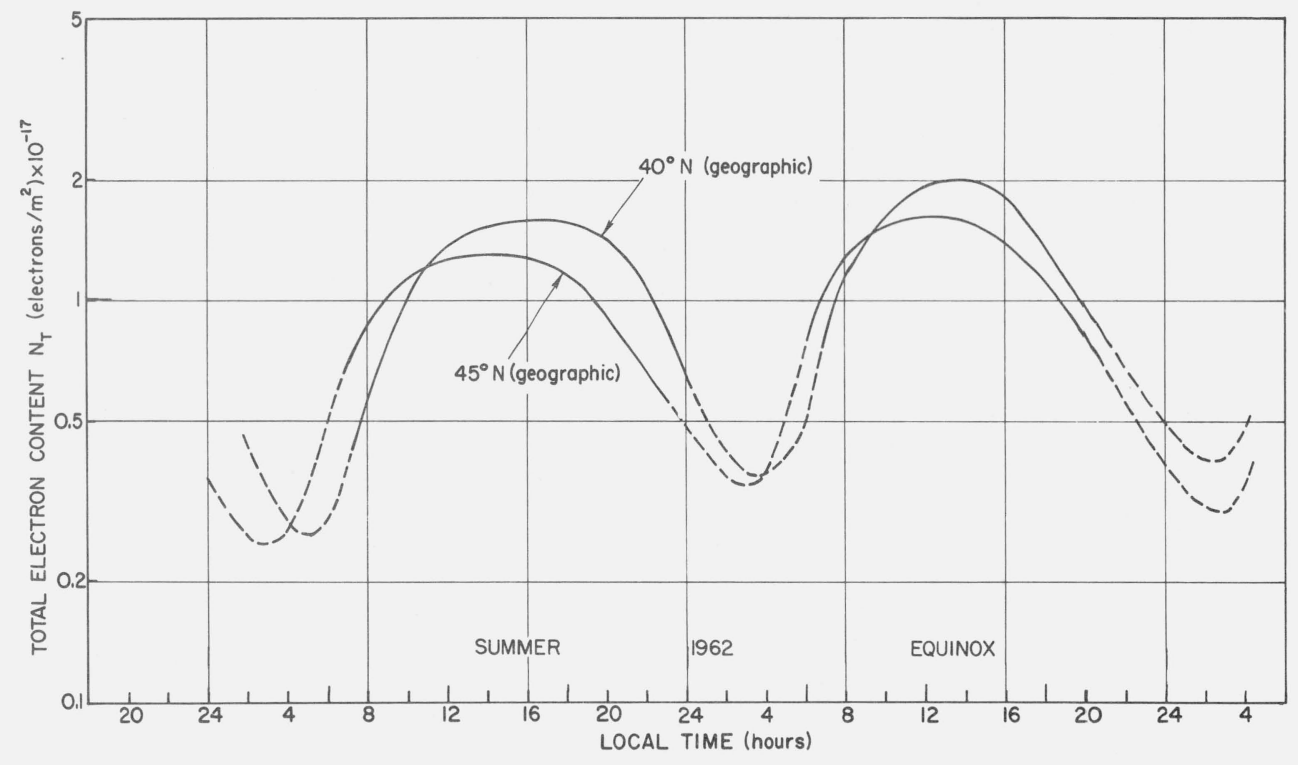

Figure 3. Mean diurnal variation of $\mathrm{N}_{\mathrm{T}}$ at $40^{\circ} \mathrm{N}$ and $45^{\circ} \mathrm{N}$ (geographic).

mean diurnal curves drawn manually through the points in figures $2 \mathrm{a}$ and $2 \mathrm{~b}$ are shown in figure 3 . The diurnal variations of $N_{T}$ at these stations appear to be similar with a daytime peak that occurs in the afternoon and a minimum before sunrise. Noon values of $N_{T}$ at Washington, however, were somewhat higher than those at Ottawa. This is not unexpected since a similar trend is found in the noon $N_{\max }$ values at these stations. It should be noted that the noon values of $N_{T}$ in March-April 1962 were slightly higher than the corresponding values in June-July 1962. This seems to be due to seasonal variation of $N_{T}$, although a small part of this seasonal variation may be attributed to the declining solar activity. During 1962 , both the diurnal and seasonal variations of $N_{T}$ at midlatitudes diminished in amplitude as compared to the variations observed by Lawrence et al., [1963] for the Boulder and Stanford data obtained from the Faraday rotation of the signals from Sputnik 3 in 1958-59. They observed a seasonal variation in the noon values of $N_{T}$ of about 2 to 1 from winter to summer and a diurnal variation of about 10 to 1 .

\subsection{Mean Diurnal and Seasonal Variation of the Equivalent Slab Thickness, $\tau$}

The equivalent slab thickness of the ionosphere,

$$
\tau \equiv \frac{N_{T}}{N_{\max }}
$$

is evaluated from the satellite observations coupled with the corresponding values of $N_{\max }$ from ionosonde observations [Ross, 1960]. For a Chapman-alpha electron density profile, we may deduce that $N_{T}=4.13$ $H N_{\max }$, or that $\tau=4.13 \mathrm{H}$ where $H$ is the scale height of the ionizable constituent. Thus, the measurement of $\tau$ can be easily referred to the scale height (or temperature) of the ionized layer, if the electron density profile is reasonably close to a Chapman model. At night, this has been shown to be expected [Duncan, 1956; Dungey, 1956] and, for the daytime, Bowhill [1962] and Nisbet [1963] have obtained equilibrium solutions which have the same electron content as the Chapman layer, to within 10 percent. In the absence of thermal equilibrium, the implication of the slab thickness is not so clear, but it should represent at least approximately the mean electron-ion temperature of the plasma.

Figure 4 shows the mean diurnal variation of $\tau$ over Ottawa for the period February to September 1962 calculated in two different ways. The curve represented by $(\mathrm{X})$ has been determined from the smoothed values of $N_{T}$ and $N_{\max }$ at 1-hr intervals from 0 to $23 \mathrm{hr}$ local mean time. The second curve of $\tau$ shown by $(0)$ has been determined by grouping the individually calculated values in similar l-hr intervals. There appears to be good qualitative agreement between the two diurnal curves of $\tau$. It is clear that $\tau$ exhibits a significant diurnal variation at least of the order of 30 percent, with a peak near sunrise period. The actual diurnal variation may not be quite as large as seen in figure 4 , since this mean diurnal curve has been developed from the data extending over a period of eight months. The occurrence of a peak in $\tau$ near sunrise has been reported by many investigators [Evans and Taylor, 1961; Lawrence et al., 1963; Titheridge, 1964]. This has been explained by the fact that sunrise occurs earlier at greater heights so that the ionization above the peak of $F$ layer will have considerably increased by the time the electron density at the peak begins to increase [Titheridge, 1964]. Also, measurements of electron temperature $T_{e}$, made by using incoherent backscatter technique 


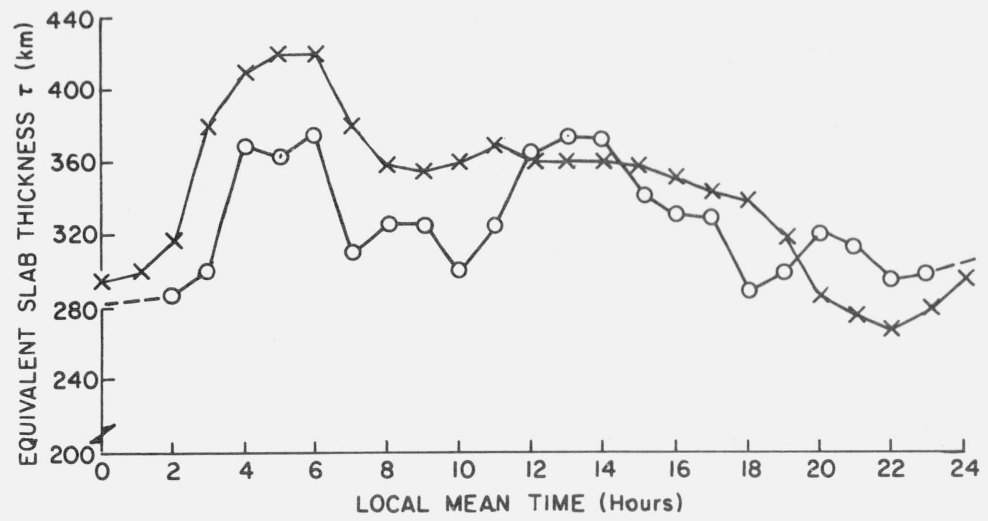

FigURE 4. Mean diurnal variation of the equivalent slab thickness $\tau$ over Ottawa in 1962, calculated from the mean diurnal variation of $\mathrm{N}_{\mathrm{T}}$ and $\mathrm{N}_{\max }(\mathrm{X})$ and from individual observation of $\mathrm{N}_{\mathrm{T}}$ and $\mathrm{N}_{\max }(0)$.

[Bowles et al., 1962] and by the Ariel satellite [Willmore et al., 1962] show evidence of a significant departure from thermal equilibrium between the electrons and ions near sunrise. This would increase the mean temperature of the electron-ion gas resulting in greater slab thickness at sunrise.

Assuming a Chapman profile for the daytime $F$ region and atomic oxygen of mass unit $=16 \mathrm{AMU}$, the noon values of $\tau$ at Ottawa in 1962 yield a scale height of about $87 \mathrm{~km}$ which corresponds to a temperature of about $1500^{\circ} \mathrm{K}$. This is in excess of the neutral gas temperature $T_{g}$, which is about $1000{ }^{\circ} \mathrm{K}$ as calculated by Nicolet [1963] from satellite drag analyses. This temperature difference may be attributed to the absence of the thermal equilibrium between charged and neutral particles. The change in $\tau$ from day to the early part of the night corresponds to a temperature change of about $470{ }^{\circ} \mathrm{K}$. It is found that in 1962, the inferred mean electron-ion temperature in the early part of the night is greater than the corresponding neutral gas temperature by about $150{ }^{\circ} \mathrm{K}$. Thus, there is a definite tendency towards thermal equilibrium between the charged and neutral particles in the nighttime ionosphere.

Seasonal variation of the noon values of $\tau$ for midlatitude ionosphere have been measured by different workers. Their results, converted to $\tau$ where necessary, are summarized in table 1 .

An examination of table 1 indicates that the seasonal variation of $\tau$ at noon in the northern hemisphere varies between 30 to 50 percent with a mean of about 40 percent, while in the southern hemisphere it is only about 20 percent. One possible reason for such wide variations in the noon values of $\tau$ may be the latitudinal differences in $N_{\max }$ at different stations, particularly in view of the fact that the mean electron-ion temperature depends critically on the ratio $Q / N_{e}^{2}$, where $Q$ is the heat input to the electrons due to solar ionizing radiation and $N_{e}$ is the electron density [Hanson, 1963].
TABLE 1. Seasonal variation of $\tau$ at noon

\begin{tabular}{|c|c|c|c|c|c|}
\hline Authors & Year & Place & $\begin{array}{l}\text { Geomag. } \\
\text { lat. }\end{array}$ & $\begin{array}{l}\text { Geomag. } \\
\text { long. }\end{array}$ & $\begin{array}{c}\text { Ratio of } \tau \\
\text { in summer } \\
\text { and winter } \\
\left(\tau_{\mathrm{S}} / \tau_{\mathrm{W}}\right)\end{array}$ \\
\hline $\begin{array}{l}\text { Lawrence } \\
\text { et al. }\end{array}$ & $1958-59$ & $\begin{array}{l}\text { Stanford } \\
\text { and } \\
\text { Boulder }\end{array}$ & $\begin{array}{l}43.7^{\circ} \mathrm{N} \\
48.9^{\circ} \mathrm{N}\end{array}$ & $\begin{array}{l}298.4^{\circ} \\
316.4^{\circ}\end{array}$ & 1.30 \\
\hline $\begin{array}{l}\text { Ross and } \\
\text { Anderson }\end{array}$ & 1959 & $\begin{array}{c}\text { University } \\
\text { Park, Pa. }\end{array}$ & $52.2^{\circ} \mathrm{N}$ & $349.1^{\circ}$ & 1.51 \\
\hline Rogers & 1959 & $\begin{array}{r}\text { Jodrell } \\
\text { Bank }\end{array}$ & $56.3^{\circ} \mathrm{N}$ & $82.5^{\circ}$ & 1.49 \\
\hline Hibberd & $1960-61$ & $\begin{array}{l}\text { University } \\
\text { Park, Pa. }\end{array}$ & $52.2^{\circ} \mathrm{N}$ & $349.1^{\circ}$ & 1.39 \\
\hline Munro & 1959 & Baxland & $42.4^{\circ} \mathrm{S}$ & $226.5^{\circ}$ & 1.16 \\
\hline Titheridge & $1960-61$ & Auckland & $41.4^{\circ} \mathrm{S}$ & $252.7^{\circ}$ & 1.20 \\
\hline
\end{tabular}

3.3. Equivalent Slab Thickness ( $\tau$ ) of the Ionosphere Over Washington and Ottawa

The mean diurnal curves of $\tau$ for Washington $\left(40^{\circ} \mathrm{N}\right)$ and Ottawa $\left(45^{\circ} \mathrm{N}\right)$ are shown in figure 5 for comparison. It is observed that $\tau$ at Ottawa is systematically higher than $\tau$ at Washington for much of the time except around midnight hours. At midday, the difference in $\tau$ at these stations is about $30 \mathrm{~km}$. This would imply that the mean temperature of the electron-ion gas in the ionosphere over Ottawa must have been about $125^{\circ} \mathrm{K}$ greater than that over Washington. This conclusion seems to be consistent with the electron temperatures observed with Aerial satellite which showed that $T_{e}$ increased with increasing latitude. Similar latitudinal trend in $\left[\left(T_{e}+T_{i}\right) / 2\right]$ at $500 \mathrm{~km}$ was noticed in the analysis of the Alouette data in the fall of 1962 [Bauer and Blumle, 1964].

\subsection{Solar Cycle Variation of the Midday Total Electron Content $\left(N_{T}\right)$ at Midlatitudes}

It is a well-known fact that the critical frequency, $f_{0} F 2$, of the $F_{2}$ layer varies markedly with solar cycle, 


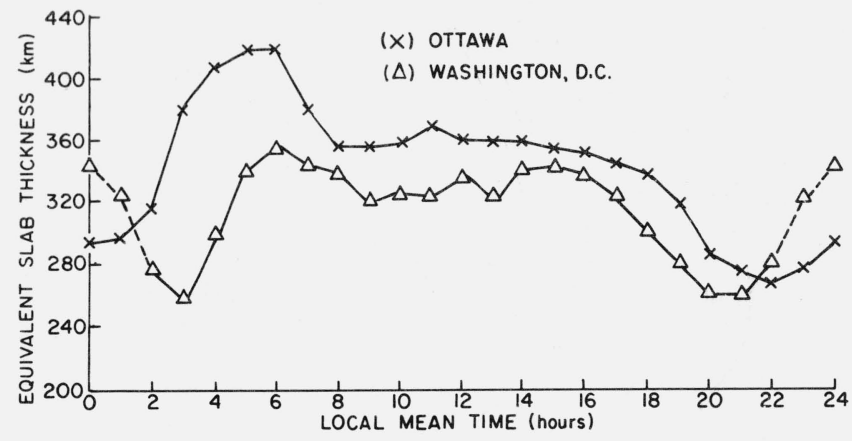

Figure 5. Comparison of mean diurnal variation of $\tau$ over Washington, D.C., and Ottawa in 1962.

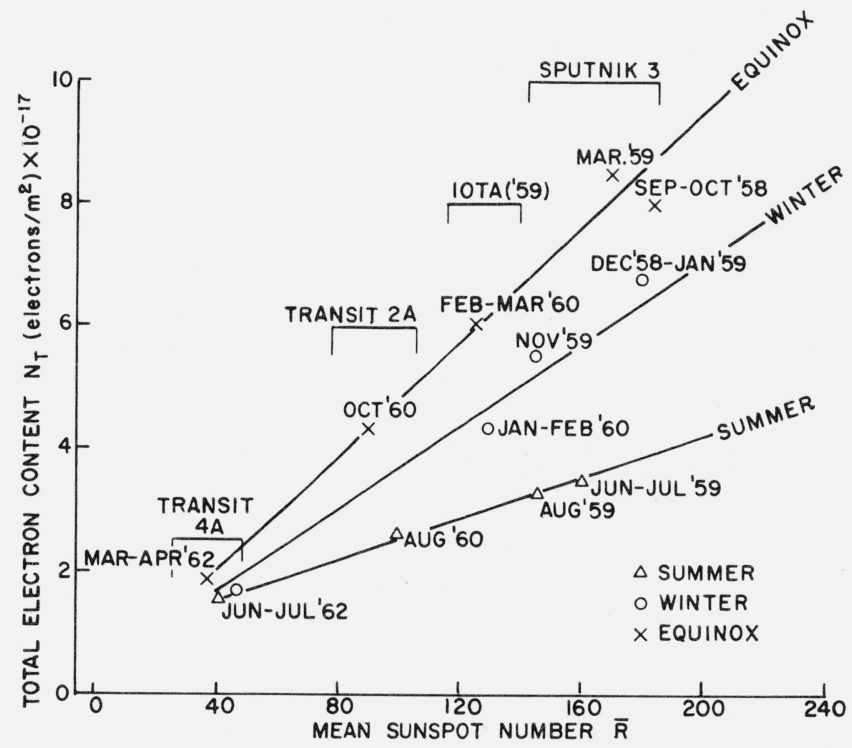

FIGURE 6. Solar cycle variation of $\mathrm{N}_{\mathrm{T}}$ of midlatitude ionosphere and the mean sunspot number, $\mathrm{R}$.

being greatest at sunspot maximum. The worldwide results have been summarized by the expression $\left(f_{0} F_{2}\right)^{2} \propto(1+0.02 \bar{R})$, where $\bar{R}$, is the mean Zürich sunspet number [Ratcliffe and Weekes, 1960]. It is of interest to determine a corresponding relationship between $N_{T}$ and $\bar{R}$. In figure 6 are plotted the mean midday values of $N_{T}$ at midlatitudes against $\bar{R}$ in different months measured by various workers during the period of declining solar activity. It is evident that $N_{T}$ increases linearly with $\bar{R}$, when the data are grouped by seasons, and we may express this empirical relationship as

$$
N_{T}=a\left[1+\frac{b}{a}(\bar{R}-40)\right] \times 10^{17} \mathrm{elec} / \mathrm{m}^{2}
$$

for $\bar{R} \geqslant 40$. The parameters $a$ and $b$ are constants which are different for different seasons. The variation of $a, b$, and the ratio $b / a$ are shown in table 2 .
TABLE 2. Seasonal variation of $\mathrm{a}, \mathrm{b}$, and $\frac{\mathrm{b}}{\mathrm{a}}$ for $\overline{\mathrm{R}} \geqslant 40$ at midlatitudes

\begin{tabular}{l|c|c|c}
\hline \hline Season & $a$ & $b$ & $b / a$ \\
\hline Summer & 1.5 & 0.017 & 0.011 \\
Winter & 1.6 & .036 & .022 \\
Equinox & 2.0 & .05 & .025 \\
\hline
\end{tabular}

The ratio $b / a$ represents the 'sensitivity' of $N_{T}$ for changes in $\bar{R}$. Examination of table 2 shows that the ratio $b / a$ seems to be comparable in magnitude in winter and equinox but appreciably smaller in summer. Thus, it appears that, in winter and equinox, $N_{T}$ responds much the same way to the changes in solar activity, even though the absolute values of $N_{T}$ might differ in these seasons. However, it is clear that in summer, $N_{T}$ increases with solar activity less rapidly than either in equinox or winter. This explains the enhanced seasonal variation of midday $N_{T}$ during a period of high solar activity. Taylor [1963] and more recently Hibberd [1964] combined their mean midday values of $N_{T}$ for summer and winter seasons with those of others and showed that, in winter, $N_{T}$ increased linearly with $10.7 \mathrm{~cm}$ solar radio flux more rapidly than in summer, which is in accord with the present results.

\subsection{Solar Cycle Variation of the Midday Slab Thickness $\tau$ at Midlatitudes}

It is generally accepted that solar extreme ultraviolet radiation is an important source responsible for heating of the $F$ region [Hunt and van Zandt, 1961]. Satellite drag measurements show that the thermopause temperature and hence the neutral particle densities at $F$ region heights vary linearly with the solar activity [Nicolet, 1963]. In figure 7 are plotted the average midday values of $\tau$ for each season against the mean sunspot number $\bar{R}$. The empirical linear relationship between $\tau$ and $\bar{R}$ may be written as

$$
\begin{gathered}
\tau(\mathrm{km})=270(1+0.005 \bar{R}) \text { for summer, } \\
\tau(\mathrm{km})=240(1+0.005 \bar{R}) \text { for equinox, }
\end{gathered}
$$

and $\quad \tau(\mathrm{km})=210(1+0.005 \bar{R})$ for winter.

Clearly, $\tau$ increases progressively from winter to summer. The seasonal variation of $\tau$ has been observed to be about 30 percent during the period of declining solar activity from 1958 to 1962. Additional scales for scale height $H$ and mean electron-ion temperature $\left.\left[\left(T_{e}+T_{i}\right) / 2\right)\right]$, assuming mean ionic mass equal to $16 \mathrm{AMU}$, are also shown in the figure 7 . Since $N_{T} \propto N_{\max } \times T, 75$ percent of the solar cycle variation of $N_{T}$, in equinox and winter, can be attributed to $N_{\max }$ variation and 25 percent to the tempera- 


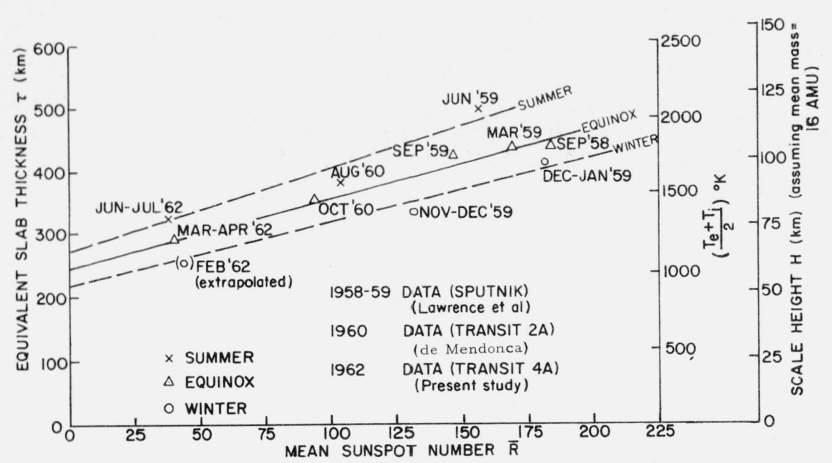

FigurE 7. Solar cycle variation of the equivalent slab thickness of the midlatitude ionosphere and the mean sunspot number, $\overline{\mathrm{R}}$.

ture variation, whereas, in summer, $N_{\max }$ and temperature seem to make approximately equal contributions to $N_{T}$ variations.

Ross and Anderson [1962] and Hibberd [1964] reported positive correlation between daytime $\tau$ and the solar activity as measured by either decimetric solar radio flux or the mean sunspot number. For southern winter, Titheridge [1964] determined the variation of $H$ with the mean sunspot number given by

$$
H=54(1+0.0023 \bar{R}) \mathrm{km},
$$

which is approximately half as large as the corresponding variation in the northern hemisphere.

The mean electron-ion temperature inferred from the measurements of $\tau$ seems to be higher than the corresponding thermopause temperature calculated by Nicolet [1963] in all seasons. The mean electronion temperature $\left(T_{e}+T_{i}\right) / 2$ at midday inferred from Sputnik 3 data and Transit $4 \mathrm{~A}$ data, assuming a Chapman profile for the $F$ region, are shown in table 3 , along with the neutral gas temperature $\left(T_{g}\right)$ determined by Nicolet. Assuming $T_{i} \simeq T_{g}$, the ratio of $T_{e} / T_{g}$ has been calculated for different seasons. It is seen that $T_{e} / T_{g}$ is of the order of 1.8 in summer but tends to be progressively lower in equinox and winter. This seasonal behavior of the ratio $T_{e} / T_{g}$ reflects similar variations in the ratio of $Q / N_{e}^{2}$ where $Q$ is the heat input to the electrons and $N_{e}$ is the electron density.

FIGURE 3. Seasonal variation of $\mathrm{T}_{\mathrm{e}}$ and $\mathrm{T}_{\mathrm{g}}$ at Midday

\begin{tabular}{c|l|r|r|r|r|l}
\hline \hline Year & Season & $\bar{R}$ & $T_{g} \simeq T_{i}$ & $\left(T_{e}+T_{i}\right) / 2$ & $T_{e}$ & $T_{e} / T_{g}$ \\
\hline \multirow{3}{*}{$1958-59$} & Winter & 180 & 1670 & 1720 & 1770 & 1.06 \\
& Equinox & 170 & 1580 & 1800 & 2020 & 1.28 \\
& Summer & 155 & 1500 & 2100 & 2700 & 1.8 \\
& & & & & & \\
& Winter & 50 & 1000 & 1125 & 1250 & 1.25 \\
& Equinox & 40 & 975 & 1220 & 1465 & 1.5 \\
& Summer & 35 & 950 & 1337 & 1724 & 1.82 \\
\hline
\end{tabular}

It is suggested by table 4 that increases in $H$ with magnetic activity are more common in equinox while the opposite seems to be true in summer. In winter, there is no significant tendency for $H$ to increase with magnetic activity. Thus, at a midlatitude station, the correlation between the scale height or mean electronion temperature appears to be rather ambiguous in contrast with the definite positive correlation between the neutral gas temperature and the magnetic activity [Jacchia, 1964]. The reason for this apparent discrepancy may be related to the nature of different heating mechanisms for the neutral and electron-ion gas. The heating of the neutral atmosphere may be accomplished through processes such as hydromagnetic wave absorption or joule losses which do not directly contribute to the plasma temperature. However, the solar EUV radiation is generally assumed to be the main source of heat in the quiet midlatitude daytime ionosphere. Ionospheric storms are considered to be either 'positive' or 'negative' depending upon whether $N_{\max }$ increases or decreases during the disturbance [Maeda and Sato, 1959]. For a given value of heat input $Q$, which may be relatively constant in a storm, these variations of $N_{\max }$ may alter the ratio $Q / N_{e}^{2}$, 
which determines the temperature difference $\left(T_{e}-T_{i}\right)$, in such a way as to cause an increase or decrease in the mean electron-ion temperature and therefore the scale height.

\section{Conclusion}

The total electron content, $N_{T}$, and the equivalent slab thickness, $\tau$, of the midlatitude ionosphere has been determined from the differential Doppler data of Transit 4A for the period February to September 1962. Significant diurnal and seasonal variations in $N_{T}$ and $\tau$ were observed. It was found that the amplitudes of these variations were diminished considerably as compared to the earlier observations made with Sputnik 3 near the peak of the sunspot cycle. The mean diurnal curve of $\tau$ showed a peak near sunrise. The change in $\tau$ from day to night was of the order of 30 percent which implied a fall in temperature of the electron-ion gas of about $470{ }^{\circ} \mathrm{K}$. The seasonal variation of midday values of $\tau$ from summer to winter in the northern hemisphere ranged from about 30 to 50 percent with a mean of about 40 percent. This is about twice the seasonal variation of $\tau$ observed in the southern hemisphere. The effect of solar activity on the daytime equivalent slab thickness, $\tau$ could be summarized by the expression of the form $\tau \propto(1+0.005$ $\bar{R})$ where $\bar{R}$ is the mean sunspot number. The daytime $\tau$ over Ottawa was about $30 \mathrm{~km}$ greater than that over Washington which implied that the mean electron-ion temperature in the $F$ region over Ottawa was greater by about $125^{\circ} \mathrm{K}$ than that over $\mathrm{W}$ ashington.

For $\bar{R} \geqslant 40$, it was found that the solar cycle dependence of noon values of $N_{T}$ could be expressed as

$$
N_{T}=[a+b(\bar{R}-40)] \times 10^{17} \mathrm{elec} / \mathrm{m}^{2}
$$

where $a$ and $b$ are constants which are different for different seasons.

The mean electron-ion temperature in the daytime ionosphere was found to be generally in excess of the corresponding neutral gas temperature determined from the satellite drag measurements. This is interpreted as an indication of the absence of the thermal equilibrium between charged and neutral particles. This inference is based, however, on an assumed profile shape for the electron distribution. Assuming $T_{i} \simeq T_{g}$, the daytime ratio of $T_{e} / T_{g}$ was estimated to be about 1.8 in summer and about 1.1 to 1.2 in winter. Reexamination of Sputnik 3 data for 1958-59 showed that the relationship between the scale height or the mean electron-ion temperature and magnetic activity appears to be rather ambiguous in contrast with the definite positive correlation between the neutral gas temperature and magnetic activity.

The recordings of Transit 4.A signals in 1962 have been very generously loaned to Stanford University through the courtesy of Guy Worsley and George Weiffenbach from the Applied Physics Laboratory of the Johns Hopkins University under Contract No. w62-0604c with the Department of the Navy. The data were originally recorded in connection with the tracking of Transit satellites under the direction of APL. Fernando de Mendonca arranged for this loan while he was at Stanford University, and much of the data reduction has been supervised by S. C. Hall. The analysis has been supported by NASA Grant NsG 30-60. R. V. Bhonsle is on leave of absence from the Physical Research Laboratory, Ahmedabad, India.

\section{References}

Aitchison, G. J., J. H. Thompson, and K. Weekes (1959), Some deductions of ionospheric information from the observations of emissions from satellite 1957 $\alpha 2-\mathrm{I}$, J. Atmospheric Terrest. Phys. 14, 236-248.

Bauer, S. J., and L. J. Blumle (1964), Mean diurnal variation of the topside ionosphere at midlatitudes, J. Geophys. Res 69, 36133618.

Blackband, W. T. (1960), The determination of ionospheric electron content by observation of Faraday fading, J. Geophys. Res. 65, 1987-1992.

Blumle, L. J. (1962), Satellite observations of the equatorial ionosphere, J. Geophys. Res. 67, 4601-4606.

Bowhill, S. A. (1962), The formation of the daytime peak of the ionospheric $F_{2}$ layer, J. Atmospheric Terrest. Phys. 24, 503-510.

Bowles, K. L., G. R. Ochs, and J. L. Green (1962), On the absolute intensity of incoherent scatter echoes, J. Res. NBS 66D (Radio Prop.), No. 4, 395-407.

de Mendonca, F. (1962), Ionospheric electron content and variations measured by Doppler shifts in satellite transmissions, J. Geophys. Res. 67, 2315-2337.

Duncan, R. A. (1956), The behavior of a Chapman layer in the night $F$ region of the ionosphere, under the influence of gravity, diffusion and attachment, Australian J. Phys. 9, 436-439.

Dungey, J. W. (1956), The effect of ambipolar diffusion in the nighttime $F$ layer, J. Atmospheric Terrest. Phys. 9, 90-102.

Evans, J. V., and G. N. Taylor (1961), The electron content of the ionosphere in winter, Proc. Roy. Soc. A263, 189-211.

Garriott, O. K. (1960), The determination of ionospheric electron content and distribution from satellite observations 1 and 2 , J. Geophys. Res. 65, 1139-1157.

Garriott, O. K., and F. de Mendonca (1963), A comparison of methods for obtaining electron content from satellite observations, J. Geophys. Res. 68, 4917-4927.

Hanson, W. B. (1963), Electron temperatures in the upper atmosphere, Space Research Proc. Intern. Space Sci. Symp. 3d, 1962, Washington, pp. 282-320 (North-Holland Co.. Amsterdam).

Hibberd, F. H. (1964), A study of the ionosphere at midlatitudes, based on total electron content, Pennsylvania State University, Ionospheric Research Scientific Report No. 213.

Hunt, D. C., and T. E. VanZandt (1961), Photoionization heating in the $F$ region of the atmosphere, J. Geophys. Res. 66, 1673-1682.

Jacchia, L. G. (1964), Influence of solar activity on the earth's upper atmosphere, Planetary Space Sci. 12, 355-378.

Lawrence, R. S., D. Jane Posakony, O. K. Garriott, and S. C. Hall (1963), The total electron content of the ionosphere at middle latitude near the peak of the solar cycle, J. Geophys. Res. 68 , 1889-1897.

Little, C. G., and R. S. Lawrence (1960), The use of polarization fading of satellite signals to study the electron content and irregularities in the ionosphere, J. Res. NBS 64D (Radio Prop.), No. 4, 335-346.

Maeda, K. I.; and T. Sato (1959), The $F$ region during magnetic storms, Proc. IRE 47, 323-329.

Munro, G. H. (1962), Diurnal variations in the ionosphere deduced from satellite radio signals, J. Geophys. Res. 67, No. 1, 147-156.

Nicolet, M. (1963), Solar radio flux and temperature of the upper atmosphere, J. Geophys. Res. 68, 6121-6144.

Nisbet, J. S. (1963), Factors controlling the shape of the upper $F$ region under daytime equilibrium conditions, J. Geophys. Res. 68, 6099-6112

Ratcliffe, J. A., and K. Weekes (1960), Physics of the ionosphere, ed. J. A. Ratcliffe (Academic Press, New York and London). 
Rogers, R. S. (1964), Measurements of the equivalent slab thickness of the daytime ionosphere, J. Atmospheric Terrest. Phys. 26, $475-497$.

Ross, W. J. (1960), The determination of ionospheric electron content from satellite Doppler measurements 1 and 2, J. Geophys. Res. 65, 2601-2615.

Ross, W. J., and D. S. Anderson (1962), The variation of ionospheric profile with season and solar cycle, Symposium on electron density profiles in the ionosphere and exosphere, ed. B. Maehlum (Pergamon Press, London).

Taylor, G. N. (1963), Lunar radar studies of the earth's atmosphere, Radio Astronomical and Satellite Studies of the Atmosphere, ed. J. Aarons, 135-150 (North-Holland Publishing Co., Amsterdam).
Titheridge, J. E. (1964), The refraction of satellite signals. II, experimental results, J. Atmospheric Terrest. Phys. 26, 177-191.

Willmore, A. C., R. L. F. Boyd, and S. J. Bowen (July 1962), Some preliminary results of the plasma probe experiments on the Areil satellite, Proc. International Conference on the Ionosphere, London, pp. 517-522.

Yeh, K. C., and G. W. Swenson, Jr. (1961), Ionospheric electron content and its variations deduced from satellite observations, J. Geophys. Res. 66, 1061-1067.

(Paper 69D7-526) 